\title{
Galectin 3 as a new therapeutic target for fibrosis and metabolic disorders in type 2 diabetes
}

\section{Dayssem khelifi ( $\nabla$ dayssem.khelifi@gmail.com )}

Department of Endocrinology, University Hospital of Charles Nicolle Ibtissem Ben Nacef

Department of Endocrinology, University Hospital of Charles Nicolle

Kahena Bouzid

Department of Clinical Biochemistry, University Hospital of Charles Nicolle

Imen Rojbi

Department of Endocrinology, University Hospital of Charles Nicolle

\section{Youssef Lakhoua}

Department of Endocrinology, University Hospital of Charles Nicolle

Nadia Mchirgui

Department of Endocrinology, University Hospital of Charles Nicolle

\section{Fethi Ben Hamida}

Research Laboratory of Kidney Diseases- LR00SP01

\section{Karima Khiari}

Department of Endocrinology, University Hospital of Charles Nicolle

\section{Research Article}

Keywords: Type 2 diabetes, Galectin 3, Fibrosis, Prevention

Posted Date: October 1st, 2021

DOl: https://doi.org/10.21203/rs.3.rs-920665/v1

License: (c) (1) This work is licensed under a Creative Commons Attribution 4.0 International License. Read Full License 


\title{
Galectin 3 as a new therapeutic target for fibrosis and metabolic disorders in type 2 diabetes
}

\author{
Dayssem Khelifi'1, Ibtissem Ben Nacef ${ }^{1}$, Kahena Bouzid ${ }^{2}$, Imen Rojbi ${ }^{1}$, Youssef \\ Lakhoua $^{1}$, Nadia Mchirgui ${ }^{1}$, Fethi Ben Hamida ${ }^{3}$, Karima Khiari ${ }^{1}$ \\ ${ }^{1}$ Department of Endocrinology, University Hospital of Charles Nicolle Tunis, Tunisia \\ ${ }^{2}$ Department of Clinical Biochemistry, University Hospital of Charles Nicolle Tunis, \\ Tunisia
}

${ }^{3}$ Research Laboratory of Kidney Diseases- LR00SP01- Tunis, Tunisia

Corresponding author : Dayssem Khelifi ( Dayssem.khelifi@gmail.com)

\begin{abstract}
Background: The objective of our research work was to identify the predictive factors of metabolic disorder and the pro-fibrotic factors which would be correlated with high levels of Galectin-3(Gal-3) in a population of patients with type 2 diabetes.

Methods: We carried out an analytical cross-sectional study.We included 260 type 2 diabetics followed in our endocrinology department.For the purpose of determining a threshold value of Gal-3,we asked for a non-diabetic control group. The medical history interview included history of diabetes, use of antihypertensive medications, lipid-lowering medication, smoking habits and physical activity. A careful clinical examination was performed for all patients and all of them underwent a biological analysis with an assay of the plasma concentrations of Galectin-3.
\end{abstract}

Results: Our study included 260 type 2 diabetics with an average age of $59.4 \pm 8$.9years. The sex ratio was 0.78 . We established a threshold for galectin-3 with the best sensitivity and specificity at $11.25 \mathrm{ng} / \mathrm{ml}$ using the ROC curve. We found a significant positive correlation of Gal-3 with age $(p<0.001)$, duration of diabetes $(p=0.024)$,systolic blood pressure $(p=0.032)$, diabetic retinopathy $(\mathrm{p}<0.001)$, body mass index $(\mathrm{p}=0.01)$, waist circumference $(\mathrm{p}<0.001)$, hypertension $(\mathrm{p}<0.001)$, dyslipidemia $(\mathrm{p}=0.023)$, triglyceridemia $(\mathrm{p}=0.029)$. An inverse association between Gal-3 level and physical activity $(\mathrm{p}=0.014)$,hypoplipemic treatment $(\mathrm{p}=0.040)$, metformin $(\mathrm{p}=0.028)$ and glomerular filtration rate $(\mathrm{p}<0.001)$ were observed.

Conclusion: We established a threshold value of Gal-3 and we discovered the clinical and biological parameters correlated with the elevation of Gal-3 which would be pro-fibrosating factors. We have also demonstrated that this lectin is a key player as a new marker and therapeutic target for the control of metabolic disorders.

Keywords Type 2 diabetes - Galectin 3 - Fibrosis - Prevention 


\section{Background}

During the last twenty years, the prevalence and incidence of diabetes mellitus have increased (1). The magnitude of the problem is such that experts have not hesitated to call it the epidemic of the 21 st century (2). The prevalence rate is increasing in the Middle East and North Africa region, reaching $12.2 \%$ (1). Type 2 diabetes is an insidious and progressive disease. It is the most common type of diabetes, accounting for around $90 \%$ of all diabetes cases [1]. In silence, it affects the body, increasing its morbidity and mortality and making it one of the heavy burdens in terms of public health (2). In fact, the risk of cardiovascular events is tripled in patients with diabetes (3). Diabetic nephropathy is the leading cause of kidney failure and more than half of people with diabetes undergo hemodialysis (4).

Diabetes causes tissue fibrosis by still poorly understood mechanisms that involve glycation products (5). A marked increase in the prevalence of type 2 diabetes is associated with a parallel increase of diabetic cardiomyopathy, characterized in particular by a fibrotic process leading to left ventricular hypertrophy and diastolic dysfunction (6). Diabetes has also been shown to induce fibrosis and glomerular sclerosis which causes diabetic nephropathy (4). These data lead to the conclusion that the primum movens of the various complications in diabetics is tissue fibrosis. Over the past ten years, research has increased on the development of new biomarkers that could diagnose and / or participate in risk stratification of cardiovascular and renal pathologies in type 2 diabetics.

Namely galectin-3 (Gal-3) which is the most studied member of the galectin family to date. It is a compound of the lectin family having a particular affinity for galactosides and more particularly for glycoproteins comprising the disaccharide N-acetyl-D-lactosamine (7). This biomolecule is expressed in many cell types and in several tissues (8). It has been shown to be involved in inflammation, fibrosis and thus tissue remodeling through the induction of fibroblast proliferation, collagen production and deposition (8).

It has a pro-fibrotic effect on the heart $(9,10)$ and kidneys $(11,12)$ as well as a role in atherosclerosis by chemoattraction (13). Furthermore, Gal-3 is identified as a metabolic disorder factor exerting a proliferative action on adipocytes (14) and an effect on insulin signaling, thus contributing to insulin resistance (15).

Therefore, the objective of our research work was to identify the predictive factors of metabolic disorder and the pro-fibrotic factors which would be correlated with high levels of Gal-3 in a population of patients with type 2 diabetes, whose early detection and effective control would prevent progression to the onset of serious complications.

\section{Methods}

We conducted a cross-sectional study with an analytical aim.

\section{Participants}

From April 2019 through June 2020, we recruited type 2 diabetic patients $(n=260)$ regardless of gender and duration of the diabetes, whose age range was between 35 and 80 years old. For statistical purposes, we requested a control group $(n=100)$ of adults who had not a history of diabetes and any drug intake that could interfere with the dosage of Gal-3. These controls were matched to cases by age and sex. 
The non-inclusion criteria for our study were heart failure, diabetic nephropathy (albuminuria $>30 \mathrm{mg} / 24$ ) and / or renal insufficiency defined as estimated glomerular filtration rate $<60 \mathrm{~mL} / \mathrm{min}$, active infection, acute or chronic inflammatory pathologies, neoplasia and pregnancy.

\section{Study Visits and Data Collection}

The medical history interview included History of diabetes (age of diabetes, current treatment of diabetes, repercussions, associated diseases), use of antihypertensive medications, lipidlowering medication, smoking habits and physical activity.

On clinical examination, we measured weight in $\mathrm{kg}$, height in metre, waist circumference in $\mathrm{cm}$, systolic (SBP) and diastolic (DBP) blood pressure in $\mathrm{mmHg}$, we appreciated peripheral pulses and neurological examination (sensitivity, motor skills, tendon reflexes). We calculated the body mass index (BMI) according to the following formula: BMI $\left(\mathrm{kg} / \mathrm{m}^{2}\right)=$ Weight $(\mathrm{kg})$ / $\operatorname{Height}^{2}(\mathrm{~m})$.

\section{Laboratory Analyses}

The following analyzes were performed for all the patients: Fasting blood sugar in mmol / 1, glycated hemoglobin (A1c) in percent measured according to the HPLC method, serum creatinine in $\mu \mathrm{mol} / \mathrm{l}$, Total cholesterol, Low density lipoprotein cholesterol, High density lipoprotein cholesterol and Triglyceridemia in mmol / 1, Gal-3 in $\mathrm{ng} / \mathrm{ml}$.

*Gal-3:

Gal-3 Assay Technique: The Gal-3 assay was performed on MINIVIDAS by ELFA (Enzyme Linked Fluorescent Assay) technique.

Description of the procedure: The principle of the assay combines the one-step sandwich enzyme immunoassay with final fluorescence detection.

Stability of the samples: For each patient, the sample was taken at each time on a lithium heparinate tube which was immediately centrifuged at $3000 \mathrm{rpm}$ for $20 \mathrm{~min}$. The plasma was then decanted and then frozen at $-80^{\circ} \mathrm{C}$ for up to six months.

Technical performances: The detection limit for galectin3 on Minividas is $2.4 \mathrm{ng} / \mathrm{mL}$ [24].

-Linearity: The dosage of Gal-3 on Minividas is linear between 3.3 and $100 \mathrm{ng} / \mathrm{mL}$.

-Drug interference: The drugs used in our study had no known influence on the dosage of Gal-3 in Minividas [24].

\section{STATISTICAL ANALYSIS:}

We calculated absolute frequencies and relative frequencies (percentages) for the qualitative variables. We calculated means, medians, and standard deviations and determined extreme values for the quantitative variables.

Intra group study: 
The comparisons of two quantitative variables on independent series were carried out by the nonparametric test of Mann and Whitney due to the non-Gaussian frequency distribution (verified by the Kolmogorov and Smirnov test).

The comparisons of several (> 2) variables on independent series were performed by the Kruskall-Wallis H test.

The links between two quantitative variables were studied by the Spearman rank correlation coefficient.

Case-control comparison:

The comparisons of two quantitative variables on independent series were carried out by Mann and Whitne's test.

The comparisons of percentages on independent series were carried out by Pearson's chisquare test.

We transformed the quantitative variables into qualitative two-way variables.

For the determination of the discriminating threshold of the quantitative variable, we established ROC curves (Receiver Operating Characteristics). After checking that the area under the curve is significantly $>0.500$, we chose as the threshold the value of the variable which corresponds to the best "sensitivity-specificity" pair.

The significance level $p$ was set at 0.05 .

\section{Results:}

Our study included 260 type 2 diabetic patients of average age $59.4 \pm 8.9$ years [range 35 and 80 years]. The sex ratio was 0.78 . The age of diabetes was 9.4 years. BMI averaged $28.69 \pm$ $5.41 \mathrm{~kg} / \mathrm{m}^{2}$ body surface area [range 17 and $48 \mathrm{~kg} / \mathrm{m}^{2}$ ]. Among our patients, 46 patients $(17.7 \%)$ had diabetic retinopathy and 63 patients $(24.2 \%)$ had diabetic neuropathy, $57.3 \%$ were hypertensive, $45.8 \%$ were dyslipidemic and $46.2 \%$ were under lipid-lowering treatment. On the therapeutic level, $11(4.23 \%)$ patients were on diet alone, $131(50.38 \%)$ patients on oral antidiabetics alone, $30(11.53 \%)$ patients on insulin therapy alone, $88(33.84 \%)$ patients on oral antidiabetics and insulin therapy and to note that $79.8 \%$ were on metformin.

The mean fasting blood sugar was $9.68 \mathrm{mmol} / 1 \pm 3.57$. The mean A1c was $8.51 \% \pm 1.87$. The mean serum creatinine was $70.9 \mu \mathrm{mol} / \mathrm{L} \pm 11.1$ with the mean creatinine clearance was of the order of $89 \mathrm{ml} / \mathrm{min}$. The mean Gal-3 value was $14.24 \mathrm{ng} / \mathrm{ml} \pm 7.32$ [range 3.30 and 69.30ng / ml]. The median concentration was $12.4 \mathrm{ng} / \mathrm{ml}$. Table I presents a comparative analysis of all the variables of interest of the cases and controls, in means, numbers and percentages.

\section{DETERMINATION OF THE THRESHOLD VALUE OF GALECTIN-3:}

For the determination and validation of a threshold value of Gal-3, we called on the control group. 
We tried 4 methods:

* First method: ROC curve

We carried out an ROC curve which allowed us to define a value of Gal-3 at $11.25 \mathrm{ng} / \mathrm{ml}$ as the best threshold of sensitivity and specificity (Figure 1). Using this cutoff, the sensitivity and specificity of the test were $64 \%$ and $55 \%$, respectively. The area under the ROC curve was 0.61 (Confidence Interval: CI95 [0.55-0.67], $\mathrm{p}=0.001$ ).

* Second method: average of Galectin-3 + 2DS of the controls

We determined the mean +2 SD (standard deviation) of the Gal-3 level of the controls, which allowed us to define a Gal-3 value at $19.25 \mathrm{ng} / \mathrm{ml}$. Using this cutoff, the sensitivity and specificity of the test were $15 \%$ and $95 \%$, respectively. $\rightarrow$ TOO LOW SENSITIVITY

*Third method: 97.5th percentile of the Galectin-3 value of the controls

We identified the 97.5th percentile of the Gal-3 level of the controls which allowed us to define a Gal-3 value at $23.18 \mathrm{ng} / \mathrm{ml}$. Using this cutoff, the sensitivity and specificity of the test were $8 \%$ and $98 \%$, respectively. $\rightarrow$ TOO LOW SENSITIVITY

* Fourth method: 95th percentile of controls

We determined the 95th percentile of the Gal-3 level of the controls which allowed us to define a Gal-3 value at $19.45 \mathrm{ng} / \mathrm{ml}$. Using this cutoff, the sensitivity and specificity of the test were $14 \%$ and $95 \%$, respectively. $\rightarrow$ TOO LOW SENSITIVITY

Finally, we retained the threshold value of $11.25 \mathrm{ng} / \mathrm{ml}$ corresponding to the best sensitivityspecificity pair.

\section{Correlations of Gal-3 level with clinical and biological factors}

Determination of the Gal-3 cut-off allowed us to study the correlations between Gal-3 levels and socio-demographic, clinical and biological parameters in our diabetic population (Table II).

\section{Discussion:}

Plasma Gal-3 is a mediator of fibrogenesis and inflammation. It has been implicated in many diseases. Particularly in diabetes, this lectin directly mediates trans differentiation in collagenproducing cells thus leading to fibrosis of target organs and accelerating the development of complications. This is because high Gal-3 values were associated with an increased likelihood of developing heart failure and nephropathy in patients with type 2 diabetes.

Several published studies have confirmed that Gal-3 is a component of the receptor complex advanced glycation products (AGEs) (16), has a profibrotic effect and is implicated in cardiovascular disease not only as a disease marker but also as a mediator of the development and progression of heart failure $(17,18)$. It has in fact been described that the level of plasma Gal-3 increases during heart failure. Data published by Seferovic and al. (19) affirm the potential role of this biomarker for the early detection of structural and functional dysfunction of the myocardium in type 2 diabetics. During diabetic nephropathy and well before the stage 
of nephron reduction, the accumulation of AGEs has been observed in different renal structures (20). A recent longitudinal analysis of 2450 participants in the Framingham Offspring cohort showed that an elevated Gal-3 at baseline predicts a rapid decline in glomerular filtration rate and an increased risk of chronic kidney disease (21).

These findings suggest that glomerular infiltration of Gal-3 positive cells may play an important role in the progression of diabetic nephropathy so that the level of expression of this biomarker may be a predictor of a poor prognosis.

Recently, Gal-3 has also been implicated in the development of metabolic disorders. It can directly cause a decrease in insulin signaling and promote inflammation of fatty tissue (22). In fact, in human tissue, Gal-3 is expressed not only by macrophages but also by fatty cells where it stimulates the differentiation of pre adipocytes into mature adipocytes (22). It causes systemic insulin resistance by acting directly on the three main target organs of insulin: inhibiting the absorption of glucose by muscle and fat cells and reducing the inhibitory effect of insulin on hepatocyte secretion glucose (23). In addition, it has been shown that Gal-3 binds to the oligosaccharide side chain of the insulin receptor thus preventing the binding of insulin to its receptor (24) and leading to inhibition of all subsequent steps of insulin signaling.

Various human and experimental studies have proven that Gal-3 is an emerging key player in metabolic disorders and a powerful factor in the development and progression of the fibrotic process in target organs (in particular the heart and kidney) in diabetic patients. It has also been shown that active fibrosis precedes the clinical manifestations of these complications by several years. Hence the interest in identifying the pro-fibrotic factors which would be correlated with high levels of Gal-3, the early detection of which and effective control would prevent the progression towards the installation of serious complications.

*In our series, we found a significant correlation between age and Gal-3 levels ( $r=0.361 ; p$ $<0.001)$. The association between age and Gal-3 levels is well established. This could be explained by the fact that the body undergoes morpho-functional changes during aging thus accelerating the progression to organ fibrosis.

*Excess weight is associated with dysfunctional adipocytes and adipose tissue rich in macrophages $(20,25)$. In addition to impaired lipid storage, the release of adipokines and inflammatory cytokines are elevated and partly explain the systemic inflammation in obese patients $(26,27)$. Notably, the association between BMI and Gal-3 levels is well established in several human studies $(17,28,29)$. Weber and $a l$. (30) described a positive correlation of intra-monocytic blood level of Gal-3 and BMI by detecting a higher expression of Gal-3 in cells of patients with type 2 diabetes. De Boer and al. (17) sought to establish the relationship of Gal-3 with cardiovascular risk factors and mortality in 7968 subjects from the general population followed for a mean duration of 10 years. They found that Gal-3 levels were correlated with BMI ( $\mathrm{p}<0.0001)$. Ho and al. (29) measured Gal-3 in 3353 participants randomly selected from the general population and followed for 3 years. They showed that Gal-3 was positively associated with BMI ( $\mathrm{r}=0.113$; $\mathrm{p}<0.0001)$. Nayor and al. (31) examined associations between Gal-3 and risk factors for cardio metabolic disease in 2946 individuals and found a significant correlation between Gal-3 and BMI ( $\mathrm{p}<0.0001)$. Weigert and al. (28) measured Gal-3 levels in a series of 83 individuals, 23 of normal weight, 30 overweight, and 30 patients with type 2 diabetes. They found a positive correlation between 
Gal-3 levels and BMI $(r=0.357 ; p=0.001)$. Likewise in our series, a significantly positive correlation between Gal-3 and BMI was observed $(r=0.2 ; p=0.01)$. Besides, we found a significantly positive correlation between Gal-3 level, waist circumference ( $r=0.260 ; p$ $<0.001)$ and hypertriglyceridemia $(r=0.136 ; \mathrm{p}=0.029)$. This could further prove the mediating role of Gal-3 in insulin resistance and indicate the implication of Gal3 in metabolic syndrome.

*We found a significant correlation between the level of Gal-3 and physical activity $(\mathrm{p}=$ $0.014)$. This could be explained by the fact that muscle activity induces an anti-inflammatory response through the production of myokines and the decrease in cytokines (adipokines) (32).

*In our study, we found a significant correlation of Gal-3 with high blood pressure $(\mathrm{p}<0.001)$ and systolic blood pressure $(\mathrm{r}=0,133 ; \mathrm{p}=0,032)$. In arterial hypertension, the evidence for the role of Gal-3 in the development of fibrosis in the liver, kidney and myocardium is well established (33). The correlation between Gal-3 and arterial hypertension found in studies on large series concerning the general population could therefore reflect a generalized fibrosis process which would be responsible for functional impairment of the heart or kidneys.

*A statistically significant correlation between patients with dyslipidemia and the level of Gal-3 was observed in our series $(\mathrm{p}=0.023)$. In addition, we found a significant inverse correlation of Gal-3 with lipid lowering treatment $(\mathrm{r}=-0.017, \mathrm{p}=0.040)$. A study conducted by Guennet and al. (34) suggests that in patients with chronic heart failure, lower plasma concentrations of Gal-3 have been identified in those who received statin therapy. Similarly, Kadoglou and al. (35) found that patients on short-term statin therapy had elevated Gal-3 compared to those on long-term therapy.

*We found a significant positive correlation between the level of Gal-3 and the duration of diabetes $(r=0.140 ; p=0.024)$. This could be explained by the fact that chronic hyperglycemia induces, under the influence of adipokines, mitochondrial oxidative stress which is increased by the excess of intracellular free fatty acids. The excess oxidative stress produces free radicals which, in turn, induce tissue inflammation leading to fibrosis (36).

*We observed the existence of a significant inverse correlation between Gal-3 and treatment with metformin $(r=-0.042 ; \mathrm{p}=0.028)$. Likewise, Weigert and al. (28) found a low level of Gal-3 in patients treated with metformin, and this effect was independent of BMI and HbA1c. This is because metformin reduces oxidative stress and AGE formation that induce Gal-3 expression (37) and this may contribute to lowering serum Gal-3 levels. Metformin has also been shown to reduce Gal-3 in human adipocytes and monocytes (30) thus indicating a direct effect of metformin on Gal-3 synthesis. Recent studies have shown that metformin exerts favorable properties against fibrosis by mechanisms that are still poorly understood. It was supported by De Broe and al. (38) that metformin exerts a nephroprotective effect by attenuating renal fibrosis, as well as an effect on the reduction of cardiac remodeling.

*We found a significant correlation of Gal-3 with diabetic retinopathy ( $\mathrm{p}<0.001)$. Expression of Gal-3 has been observed in the retinal pigment epithelium and in Muller cells. Canning and al. (39) found that deletion of the Gal-3 gene effectively prevents early retinal changes associated with diabetes such as internal blood-retinal barrier dysfunction, junction disruption, and endothelial growth factor expression. vascular thus suggesting that this lectin promotes initial retinal damage. 
*In our study, we found a significant positive correlation between Gal-3 levels and serum creatinine $(\mathrm{r}=0.264 ; \mathrm{p}<0.001)$ and a significant negative correlation between Gal-3 levels and creatinine clearance $(\mathrm{r}=-0.108, \mathrm{p}<0.001)$. Likewise, Song and al. (40) also found a significant negative correlation between the level of Gal-3 and the glomerular filtration rate in a series of 120 patients with type 2 diabetes $(r=-0.560, \mathrm{p}<0.001)$. As developed above, this further shows that Gal-3 could thus be an important player at the heart of the mechanisms of renal damage in type 2 diabetic patients.

The search for correlations between Gal-3 levels and clinical and biological sociodemographic parameters revealed:

- A significant positive correlation between the Gal-3 level and BMI ( $\mathrm{p}=0.01)$, waist circumference $(\mathrm{p}<0.001)$, hypertension $(\mathrm{p}<0.001)$, history of dyslipidemia $(\mathrm{p}=0.023)$, systolic blood pressure $(p=0.032)$ and triglyceridemia $(p=0.029)$ thus identifying a strong correlation between the number of criteria of the metabolic syndrome and the serum level of Gal-3. We also identified a significant positive correlation between the level of Gal-3 and the age $(\mathrm{p}<0.001)$, the duration of the diabetes $(\mathrm{p}=0.024))$ and diabetic retinopathy $(\mathrm{p}<0.001)$.

-An inverse association between the level of Gal-3 and physical activity ( $\mathrm{p}=0.014)$, hypoplipemic treatment $(\mathrm{p}=0.040)$, treatment with metformin $(\mathrm{p}=0.028)$ and creatinine clearance $(\mathrm{p}<0.001)$.

Act optimally and early on the modifiable factors associated with a high level of Gal-3 (reduce BMI and waist circumference, encourage regular physical activity, normalize SBP, preserve renal function, prescribe lipid-lowering treatment and metformin in the absence of contraindication) could represent a future preventive treatment strategy for fibrosing complications in diabetic patients.

\section{Conclusion}

This study is original, in fact, Gal-3 is a new marker which has not yet been integrated as a routine biological parameter. This is the first study which has the advantage of establishing a threshold value of Gal-3 and of identifying in a population of diabetics the sociodemographic, clinical and biological parameters correlated with a high serum level of Gal-3 which would be pro-fibrosing factors. Nevertheless, it would be interesting to expand the workforce and carry out a multicenter prospective study with the same methodological rigor.

To conclude, we have lifted a corner of the veil on the kinetics of Gal-3 in the type 2 diabetic population. This lectin is a key player deserving more attention as a new marker and therapeutic target for the control of metabolic disorders and offering encouraging prospects in aid in the screening, diagnosis and treatment of heart failure and diabetic nephropathy. 


\section{List of abbreviations}

Gal-3 : Galectin-3

SBP : Systolic blood pressure

DBP : Diastolic blood pressure

BMI : body mass index

A1c : glycated hemoglobin

ROC : Receiver Operating Characteristics

AGEs : advanced glycation products

\section{Declarations}

Funding:This project has been made possible by funding from research laboratory of kidney diseases (LR00SP01) and Charles Nicolle University Hospital.

Duality of interest: No potential conflicts of interest relevant to this article were reported.

Author Contributions: D.K collected the clinical data and.contributed to acquisition, analysis, and interpretation of the data and drafting of the manuscript. I.B.N and K.B planned, conceptualized the project. and contributed to interpretation of the data and revision of the manuscript. K.K supervised the analysis and interpretation of data. N.M, I.R., Y.L. and F.B.H planned and conceptualized the project. All authors approved the final draft submitted. D.K is the guarantor of this work and, as such, had full access to all the data in the study and takes responsibility for the integrity of the data and the accuracy of the data analysis.

\section{Ethics approval and consent to participate}

The study protocol was approved by the Regional Committee for Medical and Health Research Ethics. All participants provided written informed consent. 


\section{REFERENCES}

1. International Diabetes Federation. IDF Diabetes Atlas, 9th ed : International Diabetes Federation, 2019.

https://www.federationdesdiabetiques.org/sites/default/files/field/documents/idf_atlas_8e_fr.pdf

2. Association AD. 2. Classification and Diagnosis of Diabetes: Standards of Medical Care in Diabetes-2018. Diabetes Care. 1 janv 2018;41(Supplement 1):S13,27.

3. Maoui A, Bouzid K, Ben Abdelaziz A, Ben Abdelaziz A. Epidémiologie du diabète de type 2 au Grand Maghreb. Exemple de la Tunisie. Revue systématique de la littérature. La Tunisie Médicale.2019;97(2):286-10.

4. Gariana K, De Seigneux S, Martin P, Pechère-Bertschi A, Philippe J. Néphropathie diabétique. Revue Médicale Suisse.2012;8: 473-6.

5. Crestani B, et al. Le diabète : facteur de risque pour la fibrose pulmonaire idiopathique ou association fortuite? Revue des maladies respiratoires. 2004;21:153-1.

6. Lugat A, Joubert M, Cariou B, Prieur X. Au cœur de la cardiomyopathie diabétique: Les souris lipodystrophiques SKO comme modèle d'étude de la glucotoxicité. Med Sci (Paris). juin 2018;34(6-7):563-70.

7. Hirabayashi J, Kasai K. The family of metazoan metal-independent beta-galactoside-binding lectins: structure, function and molecular evolution. Glycobiology. août 1993;3(4):297-304.

8. Krześlak A, Lipińska A. Galectin-3 as a multifunctional protein. Cell Mol Biol Lett. 2004;9(2):305-28.

9. Gehlken C, Suthahar N, Meijers W, De Boer R.Galectin-3 in Heart Failure: An Update of the Last 3 Years. Heart Fail Clin.2018;14(1):75-92

10. Emet S. Galectin-3: A Novel Biomarker Predicts Sudden Cardiac Death in Hypertrophic Cardiomyopathy. The American Journal of the Medical Sciences.2018;365(6):537-543.

11. Desmedt V. Galectin-3 in Renal Pathology: More Than Just an Innocent Bystander ? .American Journal of Nephrology.2016;43:305-317.

12. Chen S, Kuo P. The Role of Galectin-3 in the Kidneys.International Journal of Molecular Sciences.2016;17(4)565.

13. Gao Z, Liu Z, Wang R, Zheng Y, Li H, Yang L. Galectin-3 Is a Potential Mediator for Atherosclerosis. J Immunol Res. 2020;2020:5284-728.

14. Bobronnikova L. Galectin-3 as a potential biomarker of metabolic disorders and cardiovascular remodeling in patients with hypertension and type 2 diabetes. VPJournal.2017;1:61-67.

15. Pingping L, Shuainan L, Min L, Gautum B, Dayoung O, Takeshi I ,et al.Hematopoietic-Derived Galectin-3 Causes Cellular and Systemic Insulin Resistance.Cell.2016;167(4):937-984. 
16. Iacobini C, Amadio L, Oddi G, Ricci C, Barsotti P, Missori S, et al. Role of galectin-3 in diabetic nephropathy. Journal of the American Society of Nephrology: JASN. août 2003;14(8 Suppl 3):S264-270.

17. de Boer RA, van Veldhuisen DJ, Gansevoort RT, Muller Kobold AC, van Gilst WH, Hillege HL, et al. The fibrosis marker galectin-3 and outcome in the general population. J Intern Med. juill 2012;272(1):55-64.

18. Martínez-Martínez Ernesto, Calvier Laurent, Fernández-Celis Amaya, Rousseau Elodie, JuradoLópez Raquel, Rossoni Luciana V., et al. Galectin-3 Blockade Inhibits Cardiac Inflammation and Fibrosis in Experimental Hyperaldosteronism and Hypertension. Hypertension. 1 oct 2015;66(4):767-75.

19. Seferovic JP, Lalic NM, Floridi F, Tesic M, Seferovic PM, Giga V, et al. Structural myocardial alterations in diabetes and hypertension: the role of galectin-3. Clin Chem Lab Med. oct 2014;52(10):1499-505.

20. Zeyda M, Farmer D, Todoric J, Aszmann O, Speiser M, Györi G, et al. Human adipose tissue macrophages are of an anti-inflammatory phenotype but capable of excessive pro-inflammatory mediator production. International Journal of Obesity (2005). sept 2007;31(9):1420-8.

21. O’Seaghdha CM, Hwang S-J, Ho JE, Vasan RS, Levy D, Fox CS. Elevated Galectin-3 Precedes the Development of CKD. JASN. 1 sept 2013;24(9):1470-7.

22. Menini S, Iacobini C, Blasetti Fantauzzi C, Pesce CM, Pugliese G. Role of Galectin-3 in Obesity and Impaired Glucose Homeostasis. Oxidative Medicine and Cellular Longevity. 2016;2016:9618092.

23. Li Y-S, Li X-T, Yu L-G, Wang L, Shi Z-Y, Guo X-L. Roles of galectin-3 in metabolic disorders and tumor cell metabolism. International Journal of Biological Macromolecules. 1 janv 2020;142:463-73.

24. Li P, Liu S, Lu M, Bandyopadhyay G, Oh D, Imamura T, et al. Hematopoietic-Derived Galectin-3 Causes Cellular and Systemic Insulin Resistance. Cell. 3 nov 2016;167(4):973-984.e12.

25. Berg AH, Scherer PE. Adipose tissue, inflammation, and cardiovascular disease. Circulation Research. 13 mai 2005;96(9):939-49.

26. Rabe K, Lehrke M, Parhofer KG, Broedl UC. Adipokines and insulin resistance. Molecular Medicine (Cambridge, Mass). déc 2008;14(11-12):741-51.

27. Rasouli N, Kern PA. Adipocytokines and the Metabolic Complications of Obesity. J Clin Endocrinol Metab. nov 2008;93(11 Suppl 1):S64-73.

28. Weigert J, Neumeier M, Wanninger J, Bauer S, Farkas S, Scherer MN, et al. Serum galectin-3 is elevated in obesity and negatively correlates with glycosylated hemoglobin in type 2 diabetes. $\mathbf{J}$ Clin Endocrinol Metab. mars 2010;95(3):1404-11.

29. Ho JE, Liu C, Lyass A, Courchesne P, Pencina MJ, Vasan RS, et al. Galectin-3, a marker of cardiac fibrosis, predicts incident heart failure in the community. J Am Coll Cardiol. 2 oct 2012;60(14):1249-56. 
30. Weber M, Sporrer D, Weigert J, Wanninger J, Neumeier M, Wurm S, et al. Adiponectin downregulates galectin-3 whose cellular form is elevated whereas its soluble form is reduced in type 2 diabetic monocytes. FEBS Letters. 19 nov 2009;583(22):3718-24.

31. Nayor M, Wang N, Larson MG, Vasan RS, Levy D, Ho JE. Circulating Galectin-3 Is Associated With Cardiometabolic Disease in the Community. J Am Heart Assoc. 31 déc 2015;5(1).

32. Paumard C. Les bénéfices de l'activité physique dans les pathologies chroniques. NPG Neurologie - Psychiatrie - Gériatrie. 1 août 2014;14(82):201-8.

33. Henderson NC, Mackinnon AC, Farnworth SL, Kipari T, Haslett C, Iredale JP, et al. Galectin-3 expression and secretion links macrophages to the promotion of renal fibrosis. Am J Pathol. févr 2008;172(2):288-98.

34. L G, T U, J K, Sh N, J H, P M, et al. Galectin-3 predicts response to statin therapy in the Controlled Rosuvastatin Multinational Trial in Heart Failure (CORONA). Eur Heart J. 17 avr 2012;33(18):2290-6.

35. Kadoglou NPE, Sfyroeras GS, Spathis A, Gkekas C, Gastounioti A, Mantas G, et al. Galectin-3, Carotid Plaque Vulnerability, and Potential Effects of Statin Therapy. European Journal of Vascular and Endovascular Surgery. 1 janv 2015;49(1):4-9.

36. Jaafar J. Maladies hépatiques chroniques et diabète.Revue Médicale Suisse.2014;10:1254-1260.

37. Schurman L, McCarthy AD, Sedlinsky C, Gangoiti MV, Arnol V, Bruzzone L, et al. Metformin reverts deleterious effects of advanced glycation end-products (AGEs) on osteoblastic cells. Experimental and Clinical Endocrinology \& Diabetes: Official Journal, German Society of Endocrinology [and] German Diabetes Association. juin 2008;116(6):333-40.

38. De Broe ME, Kajbaf F, Lalau J-D. Renoprotective Effects of Metformin. NEF. 2018;138(4):261-74.0

39. Canning P, Glenn JV, Hsu DK, Liu F-T, Gardiner TA, Stitt AW. Inhibition of advanced glycation and absence of galectin-3 prevent blood-retinal barrier dysfunction during short-term diabetes. Exp Diabetes Res. 2007;2007:51837.

40. Song G, Sun H, Han P, Ge N, Wang W, Yi T, et al. Increased serum galectin-3 levels are associated with the development of type 2 diabetic nephropathy: a novel marker for progression?. Int J Clin Exp Med.2018;11(7):7156-7164. 
Tables :

Table I: Baseline Characteristics and comparative analysis of all the variables: cases versus controls

\begin{tabular}{|c|c|c|c|}
\hline & $\begin{array}{l}\text { Cases } \\
(n=260)\end{array}$ & $\begin{array}{l}\text { Controls } \\
(n=100)\end{array}$ & $p$ \\
\hline Age (years) & 59.37 & 57.52 & 0.622 \\
\hline \multicolumn{4}{|l|}{ Gender } \\
\hline Women & $146(56.1 \%)$ & $67(67 \%)$ & \multirow[t]{2}{*}{0.072} \\
\hline Men & $114(43.9 \%)$ & $33(33 \%)$ & \\
\hline BMI $\left(\mathrm{kg} / \mathrm{m}^{2}\right)$ & $28.68 \pm 5.41$ & $28.46 \pm 4.3$ & 0.711 \\
\hline Smoking & $63(24.2 \%)$ & $11(11 \%)$ & 0.016 \\
\hline \multicolumn{4}{|l|}{ Physical activity } \\
\hline -regular & $16(6.5 \%)$ & $1(1 \%)$ & \multirow{3}{*}{$<0.001$} \\
\hline - irregular & $161(61.9 \%)$ & $91(91 \%)$ & \\
\hline -absent & $83(31.9 \%)$ & $08(8 \%)$ & \\
\hline \multicolumn{4}{|l|}{ Family history: } \\
\hline -Diabetes & $172(66.15 \%)$ & $48(48 \%)$ & $<0.001$ \\
\hline -Arterial hypertension & $153(58.8 \%)$ & $49(49 \%)$ & 0.098 \\
\hline -Dyslipidemia & $84(32.3 \%)$ & $37(37 \%)$ & 0.455 \\
\hline -Cardiovascular illnesses & $64(24.6 \%)$ & $22(22 \%)$ & 0.685 \\
\hline \multicolumn{4}{|l|}{ Personal history: } \\
\hline - Arterial hypertension & $149(57.3 \%)$ & $15(15 \%)$ & $<0.001$ \\
\hline -Dyslipiemia & $119(45.7 \%)$ & $5(5 \%)$ & $<0.001$ \\
\hline SBP en mmHg & $130 \pm 13$ & $121.8 \pm 10.38$ & $<0.001$ \\
\hline DBP en mmHg & $75 \pm 9.5$ & $65.19 \pm 8.35$ & $<0.001$ \\
\hline Fasting blood sugar $\mathrm{mmol} / \mathrm{l}$ & $9.68 \pm 3.57$ & $4.89 \pm 0.33$ & $<0.001$ \\
\hline A1c \% & $8.51 \pm 1.87$ & $5.39 \pm 0.25$ & $<0.001$ \\
\hline Serum creatinine in $\mu \mathrm{mol} / \mathrm{l}$ & $70.9 \pm 11.1$ & $62.84 \pm 5.67$ & $<0.001$ \\
\hline Total Cholesterol mmol/l & $4.80 \pm 1.26$ & $4.80 \pm 0.93$ & 0.965 \\
\hline HDL-C mmol/l & $1.13 \pm 0.25$ & $1.16 \pm 0.18$ & 0.365 \\
\hline LDL-C mmol/l & $2.79 \pm 1.08$ & $2.79 \pm 0.49$ & 0.967 \\
\hline Triglyceridemia mmol/l & $1.64 \pm 1.10$ & $1.54 \pm 0.36$ & 0.209 \\
\hline Galectin-3 ng/ml & $14.24 \pm 7.32$ & $11.80 \pm 3.75$ & $<0.001$ \\
\hline
\end{tabular}

p: significance rate; $\mathrm{n}$ : number of patients; BMI: body mass index; SBP: systolic blood pressure; DBP: diastolic blood pressure; A1c: glycated hemoglobin; LDL-C: Low density lipoprotein cholesterol; HDL-C: High density lipoprotein cholesterol. 
Table II correlations between the serum Gal-3 level and the differents parameters studied

\begin{tabular}{lll}
\hline & R & $\boldsymbol{P}$ \\
\hline Age & 0.361 & $<0.001$ \\
\hline Gender & & NS \\
\hline BMI & 0.200 & 0.01 \\
\hline Waist circumference & 0.260 & $<0.001$ \\
\hline Lifestyle: & & NS \\
Smoking & & 0.014 \\
\hline Physical Activity & -0.106 &
\end{tabular}

Associated diseases:

\begin{tabular}{lll} 
Arterial hypertension & 0.168 & $<0.001$ \\
\hline \multicolumn{1}{c}{ Dyslipidemia } & & 0.023 \\
\hline Age of diabetes & 0.140 & 0.024 \\
\hline Insulinotherapy & & NS
\end{tabular}

$\begin{array}{lll}\text { Metformin } & -0.042 & 0.028\end{array}$

Lipid-lowering treatment $\quad-0.017 \quad 0.040$

Degenerative complications:

diabetic neuropathy NS

diabetic retinopathy $<0.001$

$\begin{array}{lll}\text { Systolic blood pressure } & 0.133 & 0.032\end{array}$

Diastolic blood pressure $\quad$ NS

Biological parameters:

Fasting blood sugar $\quad$ NS

\begin{tabular}{lll} 
A1c & & NS \\
\hline Serum creatinine & 0.264 & $<0.001$ \\
\hline Clearance créatinine & -0.108 & $<0.001$ \\
\hline Total cholesterol & & NS \\
\hline HDL-C & & NS \\
\hline LDL-C & & NS \\
\hline Triglyceridemia & 0.136 & 0.029 \\
\hline
\end{tabular}

$r$ : correlation coefficient; $p$ : significance rate; NS: not significant; BMI: body mass index; A1c: glycated hemoglobin; LDL-C: Low density lipoprotein cholesterol; HDL-C: High density lipoprotein cholesterol. 
Figure

Figure 1: The ROC curve of the couple specificity sensitivity of the threshold of Galectin-3

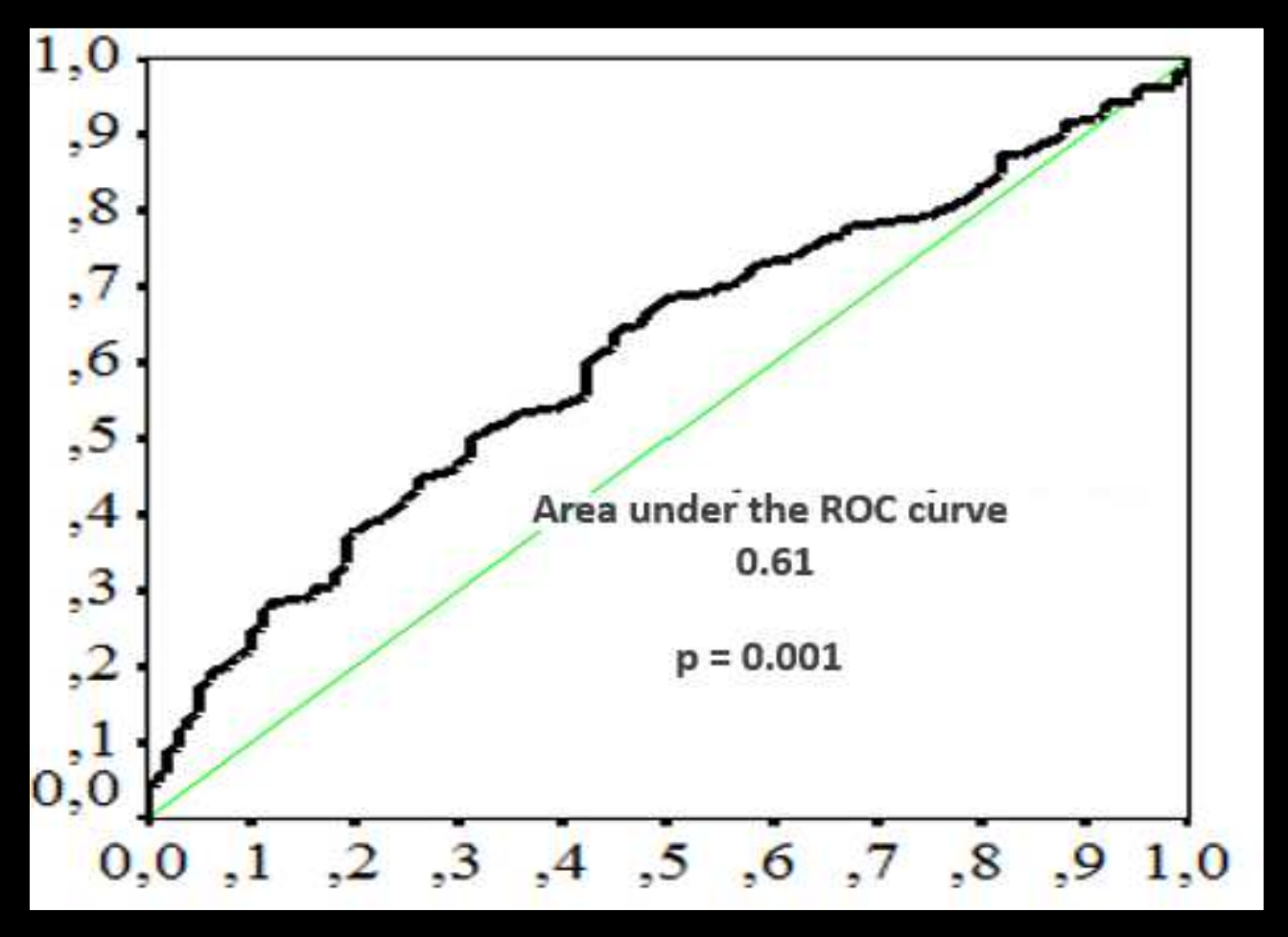

